This item was submitted to Loughborough's Research Repository by the author.

Items in Figshare are protected by copyright, with all rights reserved, unless otherwise indicated.

\title{
The implementation of integrated marketing communication (IMC): evidence from professional football clubs in England
}

PLEASE CITE THE PUBLISHED VERSION

https://doi.org/10.1080/0965254X.2019.1593225

\section{PUBLISHER}

(C) Taylor \& Francis (Routledge)

\section{VERSION}

AM (Accepted Manuscript)

\section{PUBLISHER STATEMENT}

This is an Accepted Manuscript of an article published by Taylor \& Francis in Journal of Strategic Marketing on 20 Mar 2019, available online: https://doi.org/10.1080/0965254X.2019.1593225

LICENCE

CC BY-NC-ND 4.0

\section{REPOSITORY RECORD}

Manoli, Elisavet, and lan Hodgkinson. 2019. "The Implementation of Integrated Marketing Communication (IMC): Evidence from Professional Football Clubs in England”. Loughborough University.

https://hdl.handle.net/2134/37274. 
The implementation of integrated marketing communication (IMC): Evidence from professional football clubs in England

\author{
Argyro Elisavet Manoli ${ }^{1}$ \\ (Corresponding Author)
}

School of Sport, Exercise and Health Sciences

Loughborough University

Email: E.A.Manoli@lboro.ac.uk

Ian R. Hodgkinson ${ }^{2}$

School of Business and Economics

Loughborough University

Email: I.R.Hodgkinson@lboro.ac.uk

${ }^{1}$ School of Sport, Exercise and Health Sciences, Loughborough University, Leicestershire LE11 3TU, UK. Tel: +44 (0)1509 228453.

${ }^{2}$ School of Business and Economics, Loughborough University, Leicestershire LE11 3TU, UK. Tel: +44 (0)1509 223865. 


\title{
The implementation of integrated marketing communication (IMC): Evidence from professional football clubs in England
}

\begin{abstract}
Integrated marketing communication (IMC) is considered to hold strategic value for contemporary organisations. Yet, the actual implementation of IMC by client organisations remains under researched and represents somewhat of a black box for academics and practitioners alike. The study examines the perceptions of the IMC implementation process from practitioners working within professional football clubs. The findings reveal four diverse scenarios of IMC implementation and in so doing uncover neglected oxymora in the way in which IMC theory is translated in practice. The four scenarios: strategic integration, practitioners' strategy paradox, unintentional IMC implementation paradox, and IMC absence, are each linked to a different level of practitioner IMC application. The four scenarios provide a more nuanced perspective of IMC advancement, unpacking the black box of IMC implementation to inform future practical application and research investigation.
\end{abstract}

Keywords: Integrated marketing communication; sport marketing; professional football clubs; English Premier League; strategic marketing; IMC scenarios. 


\section{Introduction}

Despite the topic of integrated marketing communication (IMC) having received considerable academic attention over the last 25 years, contradictory views as to its role and value remain. For example, Schultz et al.'s (2014, p. 455) aspirational claim that 'IMC can be recast as the base for rethinking and replacing traditional marketing theory' is in stark contrast to Cornelissen's (2001, 2003) and Ots and Nyilasy' (2017) criticisms that IMC is falsely presented as a panacea for marketing and lacks rigorous theorisation. Though the marketing literature continues to stress the need for further study to empirically unpack the organisational role of IMC, IMC implementation remains under researched. This is because the majority of extant IMC studies have focused only on the theoretical and definitional aspects of the term (Kliatchko 2005; 2008) or how IMC is implemented by marketing agencies; as a consequence, the field has overlooked IMCs strategic role for client organisations (Eagle et al.’s, 2007).

While IMC may well be important and useful in today's marketplace (Kitchen 2017), its implementation and organisational contribution require attention (Patti et al., 2017). This knowledge gap is evidenced in a recent review of IMC-focused peer-reviewed research, which shows that less than $12.5 \%$ of IMC studies (34 of 273) investigated its implementation (Manoli and Davies 2014). While the study of IMC implementation is advancing in general results "reveal that not all companies are equally likely to adopt IMC" (Šerić, 2018: 665). Such broad conclusions are in desperate need of further investigation. IMC implementation, therefore, remains somewhat of a black box for scholars and practitioners alike (Porcu et al., 2017), with disagreements persisting about the practical application of IMC (Tafesse and Kitchen, 2017). Accordingly, the ambiguity surrounding IMC has created a perceived complexity in planning and coordinating IMC implementation (Šerić, 2018), which has held the field back both in terms of IMC theorisation and its practical application. Compounding 
this lack of knowledge is that typical investigations of IMC implementation focus on marketing agencies, rather than on client organisations (Kitchen and Tao 2005; Eagle et al. 2007; Kitchen et al. 2008). This focus appears misplaced given the widely accepted argument that it is client organisations that drive the integration of IMC, not marketing agencies (Caywood and Ewing 1991; Eagle et al. 2007). The client organisation side of the IMC interface has subsequently been neglected, which has contributed to the lack of knowledge on IMC implementation. Collectively, this leads to the study's exploratory research question: how is IMC perceived and implemented in practice by client organisations?

In addressing this research question, we respond to the lack of progress made in our understanding of IMC implementation that continues to be outlined in the IMC literature (e.g. Porcu et al., 2017; Šerić, 2018; Tafesse and Kitchen, 2017). Specifically, this study focuses on the perceptions of the IMC implementation process and the extent to which IMC is being implemented among client organisations operating in the English Premier League (hereafter EPL). In so doing, this study provides much needed qualitative investigation of IMC implementation from the client side of the marketing agency/client organisation interface. The study, in turn, moves the IMC debate away from advertising and PR agencies, beyond a focus on companies located in the United States, and diverges from the tendency toward quantitative methodologies in IMC studies; as called for by Kitchen and Burgmann (2010) and Šerić (2018).

The article is structured accordingly: first, the theoretical background of IMC implementation is presented and the motivations for this exploratory study outlined. Next, the research methods are explained followed by an integrated discussion of the findings. Implications of the findings are then considered in light of the study's limitations. The article closes with concluding remarks on the IMC implementation landscape. 


\section{Theoretical background: IMC implementation}

IMC implementation appears to be on the agenda of both marketing agencies and client organisations (Kitchen et al. 2008; Kliatchko and Schultz 2014; Schultz et al. 2016). The number of services that marketing agencies now provide, and the amount of resources client organisations are willing to invest in IMC are increasing internationally (Han et al. 2004; Schultz et al. 2016). While there appears agreement between both agencies and their clients that IMC is a valuable process, there remains much ambiguity about how to advance IMC implementation in practice (Šerić, 2018). To unpack this ambiguity, we draw on the 'marketing and management-oriented IMC concept', where planning and implementation are deemed central to a client organisation-directed IMC perspective that requires client organisations to structure, consciously plan and implement communication activities in a unified, consistent and orchestrated way (Bruhn and Schnebelen, 2017). Doing so allows a focus on the specific perceptions of implementation practices in client organisations, which are central to IMC implementation advancement.

Given this theoretical standpoint, the Kitchen and Schultz (2001) IMC implementation framework is deemed the most applicable to capture the forms that IMC implementation may take. Specifically, the framework reflects the move in the IMC literature toward "a more holistic firm-wide organizational perspective" (Porcu et al., 2017) and, moreover, is based on empirical research unlike most other IMC frameworks (Kitchen and Burgmann, 2010). As Tafesse and Kitchen (2017) outline, the framework conceptualises IMC at the level of the organisation and illustrates IMC implementation advancement hierarchically, from tactical to full strategic integration. The term 'strategic integration' is synonymous with IMC implementation. Defined as "the attempt to present a consistent message across the available 
promotional mix elements" (Kitchen and Burgmann, 2010: 1), this is the most advanced state of IMC application. Nevertheless, while full strategic integration is deemed the ideal state, extant IMC implementation studies (e.g. Han et al. 2004; Kitchen et al. 2004; Kitchen et al. 2008; and Kliatchko and Schultz 2014) suggest that most organisations apply IMC at an executional or tactical level (Kitchen and Schultz 1999, 34) rather than at the organisational level for strategic ends.

The apparent reluctance to progress IMC implementation along the 4-stages of Kitchen and Schultz's (2001) IMC implementation framework, from tactical coordination (stage 1) through redefinition of the scope of marketing communications (stage 2) and the application of information technology (stage 3) towards strategic integration (stage 4) is repeatedly emphasised in extant studies (Kitchen and Schultz, 2001; Kitchen et al. 2004; Eagle et al. 2007). Indeed, practitioners are reported to have 'displayed a remarkable proclivity to be anchored (emphasis added)' in the early stages of IMC (Eagle et al. 2007, p. 965) and continue to remain at the base of Kitchen and Schultz's (2001) IMC implementation pyramid. The term 'anchored' features heavily in extant studies of IMC implementation to describe the lack of advancement to full strategic integration. Though some firms have progressed toward this ideal state, it is reported be but a handful of organisations in today's world (Kitchen et al., 2004a). This is arguably because organisations "have yet to realize a change toward the kind of consumer-focused communication which requires close collaboration between, as a minimum, the marketing, research, and finance departments (stage four)" (Kitchen and Burgmann, 2010: p. 10); pointing to the presence of inhibitors to IMC implementation. Thus, despite the widely held view that IMC holds strategic value for organisations (Kitchen and Schultz 1999; Eagle et al. 2007; Kitchen et al. 2008; Kliatchko and Schultz 2014; Schultz et al. 2016), its implementation remains predominantly at a functional or operational level in practice. This then undermines the proclaimed strategic potential of IMC and reduces the 
impact of IMC outcomes, i.e. "the organizational benefits arising from planning and implementing IMC” (Tafesse and Kitchen, 2017: 213). Specifically, and because of organisational anchoring, IMC outcomes in practice are indicative of short-term or mid-range organizational impacts at the expense of organization-wide competitive advantages that would be an outcome of full strategic integration (Tafesse and Kitchen, 2017).

Several reasons for this observed 'anchoring' are observed among extant studies, which typically highlight the impact of conceptual issues and turf-wars between the different parties involved, and organisational structure and organizational culture acting as inhibitors of IMC implementation (Porcu et al., 2017; Šerić, 2018). Moreover, in practice there remains confusion around what IMC is and continuing debate about who leads and controls the integration process (Han et al. 2004; Kitchen et al. 2004a; Dmitrijeva and Batraga 2012; Mortimer and Laurie 2017). As a result, the recent IMC literature has called for scholars to better determine the IMC practices of organizations (Šerić, 2018). This relates specifically to client organisations. Since marketing agencies appear fully aware of the strategic potential of IMC and are eager to pursue advanced levels of strategic integration (Eagle et al., 2007), they are, however, 'anchored' by the instruction of client organisations who are responsible for IMC implementation decisions.

Since it is the client organisations that sit in the drivers' seat of integration (Caywood and Ewing 1991), then, the focus of extant IMC implementation studies on marketing agencies and agency executives appears misplaced (e.g. Kitchen and Burgmann, 2010; Šerić, 2018). A research focus on the client organisation is therefore necessary in order to better determine IMC implementation practices and to examine why, after twenty years of IMC research, most organisations remain anchored in the early stages of IMC implementation (Kliatchko and Schultz 2014). As Eagle et al. (2007 p. 967) surmise, then, 'the spotlight of research attention 
now needs to turn away from ad agencies, for at best the light they shed is borrowed from the clients they serve', to client organisations.

Though clearly integral to the study of IMC, research focus on the perceptions of IMC implementation has been increasingly neglected since the early 2000s in favour of studying its impact via IMC outcomes (Šerić, 2018). Typical of these earlier studies was a focus on what IMC means conceptually from the viewpoint of practitioners (Šerić, 2018). In this exploratory study we do not seek to revisit the definitional properties of IMC, but rather address the perceptions of IMC implementation practices in line with Kitchen and Schultz's (2001) implementation paradigm to shed new light on IMC implementation advancement. Doing so will help to move IMC theory beyond its mid-range maturity level by developing a deeper understanding of its founding tenant, namely strategic integration, as highlighted by Kerr and Patti (2015).

\section{Methodology}

\section{Setting and sample}

Taking into consideration the exploratory nature of this qualitative study, as well as the need to focus on client organisations, the setting of the research had to be selected carefully. In our study, the EPL, the top tier of professional English football was selected. First, selecting companies that operate in the same industry sector would allow for any differences among sectors to be avoided. Second, an independent (with minimum state involvement) and financially growing sector, such as the EPL, would prevent for any macro-economic factors of influence, such as unstable financial times, to affect the analysis (Freestone and Manoli, 2017). The EPL is currently considered one of the fastest growing industry sectors in the UK, 
achieving a revenue increase of one $£$ billion within the last three years, and attracting considerable investments, commercial partnerships and supporter audience globally (Deloitte, 2016). This in turn has made the EPL the most commercially advanced sports league in Europe, and, according to Deloitte, the 'most-watched' sport league in the world (with more than 4.7 billion people watching its games - Deloitte 2016). The league's popularity combined with its rapid commercialisation have created the need for quick advancements in EPL's marketing communications (Parganas et al., 2015; Manoli and Kenyon, 2018). The constant need for information on behalf of both the media and the fans has driven the EPL to adopt new and innovative marketing communications practices before they become common practice in other industries. An example of this could be considered the early adaptation of new and social media by football clubs and players (Parganas et al., 2015). Following the significant commercial growth of the industry, marketing communication aspects such as sponsorship, relationship marketing and management, and brand management have also received considerable attention (McCarthy et al., 2014). EPL clubs are often considered to be remarkably advanced in those aspects when compared with both other sports leagues and other industry sectors (Manoli and Hodgkinson, 2017; Manoli and Kenyon, 2018). Taking this into consideration, focusing on EPL clubs would allow for insights to be gained from industry leaders working within highly prominent organisations.

Criterion purposive sampling (Myers 2009) of client organisations operating in the EPL was adopted. 30 client organisations participated in the study and were active members of the in one or more consecutive seasons between 2010 and 2015. Further information on the companies can be found in Appendix A. The most senior marketing and communications practitioners employed across these 30 companies were selected as the ideal interviewees based on their knowledge and ability to discuss the patterns of behaviour and organisational 
relations within the studied sample (Phillips 1994). Additional information on the interviewees can be found in Appendix B.

\section{Data generation and analysis}

Qualitative data was generated from semi-structured interviews with all 30 practitioners (one key informant per company). Interviews were conducted in person between August 2015 and March 2016. A set of core questions were developed to unpick the marketing communication practices within each of the client organisations, as well as the responders' views on IMC. The interview guide was informed by the reviewed literature and was piloted through interviews with 15 marketing communications practitioners employed by football clubs in similar industry sectors (Scottish Premier League and Greek Super League). Feedback from the pilot interviews underlined the need for projective techniques with the use of indirect interview questions to be adopted, enabling for 'truthful information to be obtained painlessly' (Haire 1950, p. 650). Applying these projective techniques involved not using the words 'integrated marketing communications' for the bigger part of each interview, in order for the practices and processes followed to be discussed accurately. The words 'integrated marketing communications' were only used towards the end of each interview for corroboration purposes. The pilot interviews also revealed a potential limitation of the study. Since the interviewees were inquired about their knowledge and perceptions of IMC towards the end of each interview, their learning and understanding was put into question. As a result, a number of the interviewees appeared to be placed in a rather uncomfortable position, which could affect the remainder of each interview. It was thus deemed necessary to avoid pressuring the interviewees in providing additional information regarding their understanding of IMC, and instead focus on reporting and interpreting their body language and tone of voice 
for supplementary evidence on the topic as Gill et al. (2008) suggest in their study. For example, when an interviewee would suggest that they know what IMC is but would appear reluctant in expanding or sharing more details about it, a note about their reaction would be kept, without inducing any additional pressure on the interviewee through further inquiries about their knowledge. Mindful of social desirability effects, efforts were made to ask similar questions in different ways, probe informants' explanations and justifications in-depth, and triangulate apparent contradictions and inconsistencies. A sample list of interview questions can be found in Appendix C. After the interviews were conducted, they were then transcribed, producing on average 6-8 pages of single spaced text per interview.

All interview transcripts were sent to the interviewees in order for any inaccuracies or misinterpretations to be highlighted and for validity checking purposes, with no changes or suggested by the interviewees. The data was analysed manually through thematic analysis (see Appendix D for key themes and illustrative quotes), which allowed for the codes identified in text to be grouped under overarching themes and sub-themes. All themes, subthemes and codes were then collated on a 'thematic map', which allowed for the specifics of each theme to be refined. The coding and data analysis process for this study followed the six phases of thematic analysis suggested by Braun and Clarke (2006, p. 16). For robustness, the codes and themes identified were verified through intra and inter coding agreement.

\section{Findings and discussion}

The analysis of the data allowed for four broad themes to be identified regarding IMCs application by client organisation practitioners. We conceptualise each aggregate theme as a different IMC implementation scenario. We present the four IMC implementation scenarios below: 
For six of the sampled companies (E, G, I, S, U, Z) there were no reported efforts to coordinate or integrate their marketing communications practices. On the contrary, these organisations favoured the presence of "multiple voices" rather than a "one-voice". These organisation presented diversity and polyphony of marketing communications as positive organisational features that allow for personalised communications to take place. The logic held was that in turn the company's brand would be enhanced. When discussing brand management practices within each of these companies specifically, the idea of a 'selfmaintained' brand that requires no internal focus was expressed, as the following quote shows:

'Everybody would say that they know the brand. There's very little sense of identity behind it. However, we feel that everybody knows the brand and we don't really have to try to be honest' (Club Z)

Here, the company's brand is considered to be universally understood and appreciated, not only by employees but also by customers, and as a result, minimum to no effort is required and devoted by the organisation to manage, promote or protect the brand. This absence of IMC is based on the misperception that the brand self-manages. Consequently, the perception of the client organisations is that any effort made to implement integration would have no effect because of the supposed self-managed brand. This logic contradicts the pursuit of strategic integration under globalisation where it is deemed imperative that "corporate and brand managers need to coordinate the actions of their global and even national brand(s) with the aim of integrating elements of promotional mix" (Kitchen and Burgmann, 2010: 2); thus, representing somewhat of an antithesis to IMC advancement. 
Yet, no measurement or assessment practices were evidence in support of this perception. On the contrary, this rather vague or myopic view as the quote above illustrates, was put forward by all six interviewees, which raises a question regarding the actual understanding and appreciation of the brand (Holm 2006; Ots and Nyilasy 2017). It can, thus, be argued that brand consistency and, accordingly, message coherency is not a priority for these client organisations and thus they do not appear to appreciate how the communications function contributes to the value of the organisation (Einwiller and Boenigkelement, 2012). After all, as De Chernatony (2001) argued, unless a shared and coherent understanding of the brand of each organisation is achieved by all employees, the brand values cannot be transferred to the other stakeholders in a clear and consistent way. In other words, consistency of the outward messages on the brand cannot be achieved, unless coherency on the brand is accomplished internally, something that these six companies currently lack.

After all six interviewees suggested that they had not even heard of the words integrated marketing communications' before the interview was conducted, the author presented them with a brief explanation of IMC (based on Kliatchko's definition of 2008), the reaction to which can be better illustrated through the following quote.

'The words inflate in your mouth. Integrated marketing communications sounds like an interesting combination of words an agency might use to sell their programmes to you. But in the real world they would make no sense' (Club S).

As the quote demonstrates, the idea of IMC was met with scepticism on whether it can be applied or whether it is even relevant in the 'real world'. Interviewees logic was that the fast pace of the industry and the reactivity that defines the majority of their actions would not allow for a process of integration to take place. One explanation for this reported scepticism could be that practitioners' lack knowledge on IMC and either fear what they do not know or 
are insecure about their lack of knowledge thus leading to negative retorts. This observation is a departure from extant IMC studies that have specifically examined perceptions of IMC and reported that all cases (e.g. client organisations, customers, and/or agencies) had a sense of the meaning of IMC, though these sometimes differed (Šerić, 2018). Yet here, these organisations had no grasp of IMC, something that was also evident from the interviewees' reactions and reluctance to elaborate on their perceptions of IMC when asked, which challenges the assumptions that all parties recognise IMC as a valuable process even if they disagree about the form this should take.

Taking both their practices and their lack of knowledge and appreciation of IMC into consideration, scenario 1 presents a situation in which IMC is absent whereby practitioners do not have knowledge of IMC and there appears to be no implementation of IMC. This scenario, then, contradicts the latest studies on IMC which argue that IMC is widely appreciated and implemented (e.g. Kliatchko and Schultz 2014; Patti et al., 2017), albeit at a tactical level. With reference to Kitchen and Schultz's (2001) IMC stage model, it is observed that a level exists below the base of the pyramid where IMC does not exist within functional practices. This finding underlines the need for further research on practitioners' views and practices in order to prevent IMC theorisation falling adrift of actual IMC implementation in practice.

\section{Scenario 2: Unintentional IMC Implementation Paradox}

A different six client organisations (A, D, M, P, AC, AD) offered an interesting oxymoron, suggesting that integration occurs on a tactical level within their organisation, but without the practitioners being aware of what IMC actually is. In other words, early IMC features emerged unintentionally: 
'But not particularly in a specific structured way. It is more in an instinctive way. I think we end up integrating unintentionally, almost organically' (Interviewee A).

The notion of unintentionally progressing toward IMC integration was emphasised by all six interviewees, with their perceptions depicting characteristics of Kitchen and Schultz's (2001) stage 1 and stage 2 of IMC implementation. According to the interviewees, integration is a concept that is evolving 'organically' within each company, which encourages employees to collaborate and attempt to manage the coherency of the company's marketing communications messages. Interpersonal and cross functional communication within the organisation was thus apparent (e.g. Kitchen and Schultz, 2001). The interviewees suggested that a less structured and rather elementary integration practice is followed, and this involves the coordination of the messages promoted by the company, the alignment of outwards communications, and the control of the potential touch points between the company and the customers; indicative of Kitchen and Schultz's (2001) stage 2 of IMC implementation. This is implemented through a process resembling Schultz' (1992) idea of an Integration Czar within the organisation, in which outward communications and brand alignment falls under the remit of one employee's job, as opposed to being an organisation-wide initiative. This employee is often the marketing or the communications director of the company, who oversees the checking and approving of any message that originates from the company, while controlling and ensuring that whatever is communicated is coherent and consistent with the organisation's brand, or as the interviewees argued:

'It is a checking point, a new thing. We have to send him most things, I think, and he checks it. When it's approved, we get the ok and we push it out' (Interviewee Y).

The problems or challenges encountered in the alignment of communications, however, and the way in which they were mentioned by the interviewees suggest that the processes are yet to be formally set in place. The concept of integration was presented to be a rather recent idea 
within each organisation, with a degree of perceived novelty. The way in which each client organisation's brand is managed signifies the weaker organisation-wide integration efforts:

'We are now beginning to do this (IMC), because it makes sense. But coordination did not really start but last year. No one knew what the brand was about. In the last 12 months, we have started a conversation. We've built an identity which we are trying to communicate' (Interviewee AD).

Within the unintentional IMC implementation paradox scenario, stages 1 and 2 of Kitchen and Schultz's (2001) IMC stage model are reached unintentionally through the organic emergence of IMC practices.

This integration oxymoron raises a number of questions on the efficiency of the said companies' marketing communications practices and their integration efforts. While evaluating this implementation would require additional investigation into the organisations where the phenomenon can be studied, the paradox identified can be linked with the early studies conducted by Cornelissen $(2001 ; 2003)$ and Cornelissen and Lock (2000) who argue that integration has been practiced by marketers long before IMC was defined or noticed by academics, explaining the unintentional, organic emergence of IMC. Thus, as Schultz and Kitchen (2000b) and Kliatchko and Schultz (2014) claim, the early pursuit of IMC integration is inevitable in some organisations owing to contemporary marketplace conditions.

\section{Scenario 3: Practitioners' Strategy Paradox}

The majority of the interviewees (17 out of 30) suggested that there exists yet another paradox in IMC's implementation. These interviewees argued that they are all aware of what IMC is and are in fact confident that they fully understand what it entails, including its 
strategic nature. The way in which IMC is implemented in the companies, however, does not allow for organisation-wide integration to be achieved, as the following quote suggests.

'To a certain extent yes (we implement IMC). Up to the point where the needs and means allow us to. IMC is something all companies would like to strive for, through some clear strategic ideologies and a clear strategy over the course of many seasons... But this is a challenging proposition... We'd like to be like that, but we do not have the resource to invest to a whole committed integrated strategy that requires infrastructure, investment and a clear direction. We are playing catch up most of the time' (X, p. 237)

As the quote shows, the companies appreciate the strategic role IMC and the potential its implementation can have to generate value for the whole organisation, yet their practice of integration remains fragmented at the organisational-level. This integration scenario suggests that a practitioners'strategy paradox exists, which is described as a discrepancy between managerial intention to support and implement IMC strategic integration in a structured way on one hand, and the limited capacity of IMC to feature in strategy development and implementation on the other; as the following quote illustrates:

'We care about our identity, we protect our brand, we want to be aligned. But it is not that simple or easy. As you know, the industry is moving very fast, maybe too fast for any planning or strategizing to happen. We try and integrate our messages, we try to represent our brand as best as we can, but a full integration is not something we can plan to have. At least not yet' (T, p. 199)

As both quotes show, these practitioners seem to appreciate the strategic nature of IMC, but strategic implementation cannot take place due to perceived organisational constraints that inhibit the advancement of IMC implementation to full strategic integration. The obstacles to its implementation presented by the interviewees allow us to shed light on the true reasons behind this paradox, which despite its earlier mention in academic studies (Eagle et al. 2007; 
Dmitrijeva and Batraga 2012; Schultz et al. 2016), has yet to be further examined. Specifically, three barriers emerged:

First, eight interviewees $(\mathrm{C}, \mathrm{F}, \mathrm{J}, \mathrm{L}, \mathrm{N}, \mathrm{O}, \mathrm{Y}, \mathrm{AB})$ appeared to be sceptical regarding strategic integration due to a number of challenges that, according to them, affect IMC's implementation from reaching its full strategic potential: the reactivity and fast pace of the industry; the lack of human and financial resources they have; and, the wide and varying demographics of their customers. Interestingly, IMC has been celebrated within academia for assisting organisations in achieving 'economies of scale' in marketing communications efforts and allowing them to respond to the increasing demands of their diverse costumers (Luxton et al. 2015; Keller 2016). Yet, this view appears to be contradicting the practitioners' views. This contradiction allows for questions to be raised on the actual reasons behind their current integration scenario, suggesting that their reluctance to implement IMC strategically might be due to their own (or their client organisation's) attachment to the current marketing communications practices and a potential fear of change to something new. This would then suggest that Eagle et al.'s (2007) argument that agency practitioners are intentionally reluctant to progress to strategic integration also applies to client practitioners who demonstrate a rather superficial appreciation of the strategic integration benefits, while intentionally persisting with IMC implementation at levels 1 and 2 following the stages of IMC development (Kitchen and Schultz, 1999).

Second, four interviewees $(B, Q, R, V)$ suggested that the paradox exists when the organisation is in the process of transitioning from the status quo to something new e.g. restructuring. All four client organisations had recently gone through a restructuring process ${ }^{1}$ which allowed for the marketing and communications teams to merge and for

\footnotetext{
${ }^{1}$ Unfortunately, and despite the author's efforts, the interviewees did not disclose any additional information on this restructuring process.
} 
interconnectivity and cross-functional communication within the organisation to be enhanced. This restructuring process resembles the reformation process highlighted by Eagle and Kitchen (2000) and Christensen et al. (2008) as a potential way to overcome structural barriers for IMC. It could thus be suggested that progressing to the final stage of integration will take place once transitional processes are completed, allowing the organisations to overcome the discrepancy between the interviewees' appreciation of IMC's strategic nature and the way in which it is typically implemented.

Third, five interviewees $(\mathrm{H}, \mathrm{K}, \mathrm{T}, \mathrm{W}, \mathrm{X})$ questioned whether strategic integration is even possible, but without offering any reasons behind their views. Following a closer look at the notes and recordings of these interviews, it could be argued that their true understanding of what IMC entails was questionable. If these practitioners do not truly appreciate what IMC entails, they may be thus be unable to drive strategic integration. In other words, the practitioners' strategy paradox exists in these companies due to practitioners' limited understanding of what IMC strategic integration should look like. This underlines the early arguments of Rose (1996) for practitioners' education and knowledge dissemination in IMCs. More than this, it supports contentions in the IMC literature that ambiguity surrounding the meaning of IMC and strategic integration specifically has caused a perceived complexity in how to plan and coordinating IMC (Šerić, 2018), and in turn, undermining its full realisation in practice. This once again highlights the need for further research on practitioners (Ots and Nyilasy 2017) as well as the lack of focus on client organisations in the past that has seemingly perpetuated this practitioners' strategy paradox. 
The remaining company (AA) mirror the characteristics of IMC strategic integration as represented in the IMC literature (Kitchen and Tourky 2015; Kitchen and Schultz, 2001; Luxton et al., 2015). According to the interviewee, IMC's implementation includes both a number of processes and a company-wide concept that is acknowledged and respected throughout the organisation by all employees. The strategic role of IMC is further enhanced by the adopted structure within the organisation, and the processes that are in place in order to harness IMC for competitive advantage creation.

As the interviewee argued, IMC is not perceived as a marketing communications practice but as a 'business priority', which underlines the importance it receives throughout the organisation. Members of various teams are expected to appreciate and implement integration, while representing the brand appropriately and communicating and collaborating openly with members of other teams. Strategies are put in place for a number of functions throughout the company, which allow for a more coordinated organisational approach to be followed, as guided by the strategy of the organisation. This strategy, according to the interviewee, safeguards the coherency and consistency of the company and ensures that continuity exists between seasons. The word 'strategy' was used frequently in combination with IMC practices (e.g. planning, checking and re-evaluating) and on measuring and assessing the results of their marketing communications efforts. The latter descriptions matched closely to the communication objective-setting practices outlined by Patti et al. (2017) where processes and systems are put in place to track targets set annually, monthly and weekly. Here, relations between teams were described as highly collaborative, where feedback on other departments' work was encouraged, in order for a company-wide evaluation to be achieved; collectively providing a real-time detailed view on the progress of all marketing communications efforts. 
According to the interviewee, a significant restructure took place within the organisation that allowed for the current processes and systems to be designed and developed, and for the collaborative culture to be adopted. More details on the restructuring process and its duration were not provided since the interviewee joined the company after the process had been completed. The only information provided on the restructure is that it was a company-wide effort that was not limited to the marketing, communications and commercial teams, but included almost all departments of the organisation resulting in an organisational and cultural shift toward full strategic integration. Though limited insights were gathered on the preceding organisational structure and culture, it was apparent that the development of cross functional cooperation, a clear customer focus and strong organizational commitment were developed during the restructure in the place of a results-driven focus and high internal competitiveness; a set of conditions that are deemed essential in IMC implementation (Tafesse and Kitchen, 2017) with the removal of inhibitors associated with weaker IMC implementation (Porcu et al., 2017). The characteristics presented, thus, point to the structural conditions that will advance IMC implementation, as called for by Keller (2016).

\section{Integration scenarios and their implications}

The findings of the study indicate that strategic integration (scenario 4) — the practice of implementing IMC strategically—represents the 'best-case' scenario, but one that few client organisations achieve (1 out of 30 ), in the context of this study. While this is inevitably depended on the nature of the client organisations of the studied context, EPL football clubs, ironically considered some of the most advanced organisations in terms of marketing communication management (Manoli and Kenyon, 2018), it might also be an indication of a wider lack of investigation of IMC's implementation, especially by client organisations. 
Somewhat paradoxically, then, though strategic integration has gained and sustained a high degree of popularity within academia, there is still a long way to go before strategic integration becomes a frequent phenomenon among practitioners. As Ots and Nyilasy (2015: 132) appropriately surmise "despite the theoretical agreement about the strategic relevance and benefits of IMC, integration often is problematic in practice". This could in turn suggest that the IMC literature has so far been presenting a rather optimistic, but possibly unrealistic, representation of IMC implementation in practice. Of the four IMC scenarios, the practitioners' strategy paradox in which a discrepancy exists between the practitioners' appreciation and implementation of IMC appears to be the most popular scenario in practice (17 out of the 30). While the existence of this discrepancy has been noted before (Eagle et al. 2007; Dmitrijeva and Batraga 2012), this study provides three potential reasons for the existence of this paradox.

First, eight interviewees remained sceptical regarding strategic integration, despite their proclaimed appreciation of IMC and its strategic value, while maintaining a proclivity to their current tactical integration practices and processes. Their intentional predisposition for this discrepancy between appreciation and implementation originated from the idea that IMC might be impractical and difficult to achieve in practice, an opinion also voiced by the critics of IMC (Cornelissen and Lock 2000; Cornelissen 2001; 2003). Consequently, a less strategic but already tested integration practice that produces quick and easy results is favoured over a long-term strategic approach.

Second, client organisations appeared to be trapped in the practitioners' strategy paradox unintentionally, while in the process of trying to achieve strategic integration. These organisations aspire to progress to strategic integration through structural advancement and are currently in the transitional stage, while waiting for the results of their recent restructuring process to materialise. This process resembles the redesign suggested by Christensen et al. 
(2008) who argue that it allows for any obstacles to be overcome and for new concepts and processes to be adopted. It could consequently be argued that these companies are trapped in the scenario unintentionally for a limited, yet undefined, amount of time, until they progress to strategic integration.

Third, a potential vicious circle of integration that leads to an unintentional anchoring in the paradox was identified in the companies where the practitioners' understanding of IMC's potential is limited. Subsequently, five client organisations were trapped in the paradox unintentionally due to their limited appreciation and/or understanding of IMC's potential, something that Mortimer and Laurie (2017) have also argued in their work. The limited research available on clients and their implementation of IMC, combined with the need for additional evaluation of practitioners' true appreciation of IMC, underline the need for further research on the topic.

The third scenario-unintentional IMC implementation paradox - occurs when practitioners do not know what IMC is, but IMC is implemented unintentionally resulting in an organic emergence of IMC. As the practitioners argued, this happens in an 'organic', 'instinctive' or 'unintentional' way in six (out of 30) companies examined. Based on the practitioners' ability to implement tactical integration unintentionally, it could be argued that applying IMC might not be such a laborious and demanding process, as Schultz' (1992) originally suggested. An additional point that is worth noting is whether through their participation in the study practitioners changed their actions based on new knowledge of IMC. If such a change can be detected, then it could be suggested that progressing to the next level of IMC is a matter of dissemination of information, education and potential training.

The final scenario identified - IMC Absence - depicts a scenario whereby practitioners do not know what IMC is and consequently do not implement it (unintentionally or intentionally), 
consistent with lack of IMC knowledge having been identified as an inhibitor of IMC implementation (Ots and Nyilasy, 2015). This scenario contradicts latest IMC studies that suggest integration is widely spread and implemented in all companies (Kliatchko and Schultz, 2014). As argued earlier in the study, client practitioners have been overlooked in the investigation of the IMC marketing agency / client organisation interface, subsequently the application of IMC theory has often been presented under an optimistic lens when many client organisations do not even practice integration (six out of 30 in this study). Interestingly, more than two decades after the discussion on IMC and strategic brand management begun, the voice of practitioners' on IMC implementation is still in its infancy. As Kliatchko (2005) and Schultz et al. (2013) have argued, the significant definitional issues regarding IMC have in fact hindered its implementation and obstructed scholars from focusing on IMC's practical issues, which might have perpetuated the existence of barriers and misconceptions around IMC application. 
Figure 1. IMC Implementation Paradigm

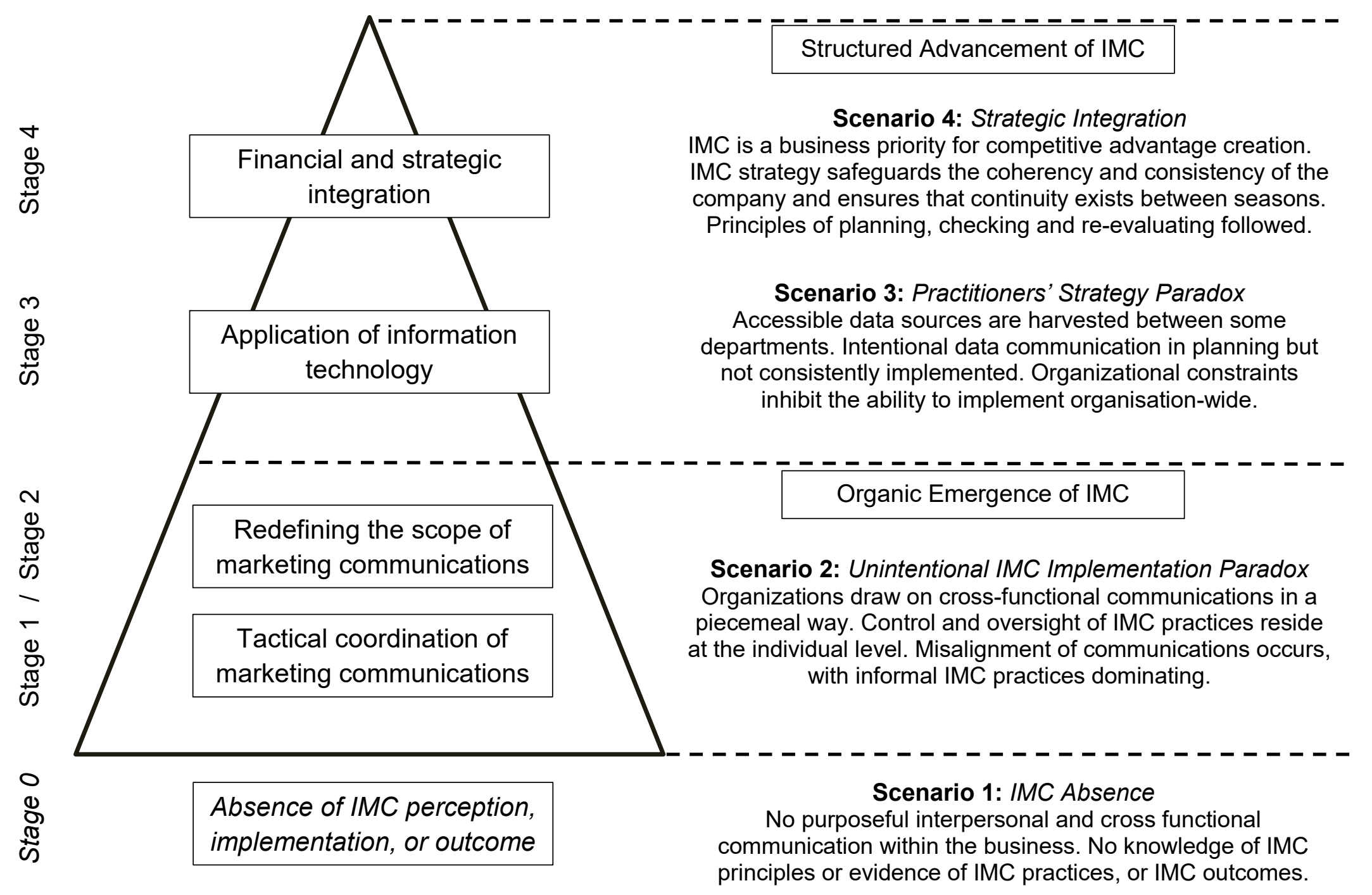

Note: Adapted 'IMC - a four stage model' from Kitchen and Schultz (2001: 108). 
The four integration scenarios uncovered by the study and shown visually in Figure 1 provide novel insight into the way and extent to which IMC is viewed and implemented by client organisations. These four scenarios extend Kitchen and Schultz's (2001) IMC stage model by presenting the IMC implementation landscape as examined among professional football clubs. In so doing, the study captures scenarios generated from the perceptions of those implementing IMC at various levels and the nuances that exist in the hierarchical IMC implementation development process. These empirically derived scenarios, thus, provide a wider view of practitioners' perceptions and implementation of IMC, within an industry sector, and allow for a more comprehensive and rounded understanding of the black box of IMC implementation. In this regard, the perceptions of IMC implementation displayed by client organisations largely represent the "traditional inside-out company-oriented view" (Finne and Grönroos, 2017, p. 447). Thus, the implementation of IMC in practice appears to fall a long way short of the "customer-centric, outside-in view" of IMC (Finne and Grönroos, 2017, p. 447), as captured in scenario 4.

\section{Limitations and further research}

Several limitations of this research need to be acknowledged. First, focusing on a single research setting may raise concerns on any efforts to generalise the findings. However, given that this exploratory study was designed to improve understanding and knowledge about practitioners' perceptions and implementation of IMC, it is argued that the research was following what Yin (2009, p. 38) calls 'analytic generalisation', that is detecting any patterns expected in the data, and as a result allowing the findings to contribute to theory testing and development. Therefore, the author does not aim to generalise the findings of this study to the wider population, but instead to identify and underline the detailed and suggestive insights 
that can be transferred in other settings. Second, data were generated from a single respondent in company sampled and while the number of staff involved in marketing within them is very small, seeking the opinions of wider organisational stakeholders would have generated greater validity in the data reported. It is suggested that additional research on more practitioners, their views and practices could further enrich the existing knowledge on IMC's appreciation and implementation, while a potential ethnographic or grounded theory study would allow for practitioners' true appreciation of IMC to be assessed and more details on the restructuring process through which integration occurs strategically be acquired. Third, the purpose of this study was to examine integration patterns through practitioners' views and practices; hence no assessment or evaluation was attempted on the potential success of their integration practices. A longitudinal investigation of the companies and their marketing communications practices would provide the opportunity to evaluate the success of their integration efforts, identity the barriers to integration and better understand the paradoxes identified, while allowing for both effective and ineffective outcomes to be examined. This is a worthy avenue for future research.

\section{Conclusion}

While IMC is often regarded as a well-researched topic in academia, the study of its implementation from the client organisation perspective remains in its infancy. Despite of this lack of attention, recent studies argue that IMC's implementation is widespread and potentially universal. The study aimed to investigate how IMC is implemented in practice by focusing on 30 client organisations through in-depth interviews with their most senior marketing employee. The findings illustrate that IMC application extends beyond what academia has captured so far by identifying four diverse scenarios and in so doing uncover 
neglected oxymora in the way in which IMC theory is translated in practice. The following four scenarios: strategic integration, practitioners 'strategy paradox, unintentional IMC implementation paradox and IMC absence, are each linked to a different level of practitioner IMC application. These four IMC implementation scenarios provide a comprehensive view of the integration landscape, unpacking the black box of IMC implementation to inform future research investigation.

\section{References}

Braun, V., and Clarke, V. (2006), "Using thematic analysis in psychology", Qualitative Research in Psychology, 3 (2), 77-101.

Bruhn, M. and Schnebelen, S. (2017), "Integrated marketing communication-from an instrumental to a customer-centric perspective", European Journal of Marketing, 51(3), 464489.

Caywood, C., and Ewing, R. (1991), “Integrated marketing communications: A new master”s degree concept”, Public Relations Review, 17 (3), 237-244.

Christensen, T.L., Firat, F.A., and Torp, S. (2008), “The organisation of integrated communications: toward flexible integration", European Journal of Marketing, 42 (3/4), 423 452.

Cornelissen, J. P. (2001), "Integrated marketing communications and the language of marketing development”, International Journal of Advertising, 20 (4), 483-498. 
Cornelissen, J. P. (2003), "Change, continuity and progress: the concept of integrated marketing communications and marketing communications practice", Journal of Strategic Marketing, 11 (4), 217-234.

Conrnelissen, J. P., and Lock, A. R. (2000), “Theoretical Concept or Management Fashion? Examining the Significance of IMC", Journal of Advertising Research, 40 (5), 7-7.

De Chernatony, L. (2001), “A model for strategically building brands”, The Journal of Brand Management, 9 (1) 32-44.

Deloitte (2016), Annual Review of Football Finance. Manchester: Deloitte.

Dmitrijeva, K., and Batraga, A. (2012), "Barriers to Integrated Marketing Communications: The Case of Latvia (small markets)", Procedia - Social and Behavioral Sciences, 58), 10181026.

Eagle, L., Kitchen, P.J, and Bulmer, S. (2007), "Insights into interpreting integrated marketing communications", European Journal of Marketing, 41 (7/8), 956-970.

Einwiller, S. A., and Boenigk, M. (2012), "Examining the Link Between Integrated Communication Management and Communication Effectiveness in Medium-Sized Enterprises", Journal of Marketing Communications 18 (5), 335-361.

Ewing, M. T., Du Plessis, E., and Foster, C. (2001), “Cinema advertising reconsidered", Journal of Advertising Research, 41 (1), 78-85.

Finne, Å. and Grönroos, C., (2017), “Communication-in-use: customer-integrated marketing communication”, European Journal of Marketing, 51 (3), 445-463. 
Freestone, C. J., and Manoli, A. E. (2017), "Financial fair play and competitive balance in the Premier League", Sport, Business and Management: An International Journal, 7 (2), 175 196.

Gill, P., Stewart, K., Treasure, E. and Chadwick, B. (2008), "Methods of data collection in qualitative research: interviews and focus groups", British Dental Journal, 204 (6), 291-295. Haire, M. (1950), "Projective Techniques in Marketing Research", Journal of Marketing, 14 (5), 649-656.

Han, D., Kim, I., and Schultz, D.E. (2004), “Understanding the diffusion of integrated marketing communications", Journal of Advertising Research, 44 (1), 31-45.

Keller, K. L. (2016), “Unlocking the Power of Integrated Marketing Communications: How Integrated Is Your IMC Program?”, Journal of Advertising, 45 (3), 286-301.

Kerr, G. and Patti, C. (2015.), "Strategic IMC: From abstract concept to marketing management tool”, Journal of Marketing Communications, 21 (5), 317-339.

Kitchen, P.J. \& Burgmann, I. (2010), Integrated marketing communication, New Jersey: John Wiley \& Sons, Ltd.

Kitchen, P. J., and Schultz, D.E. (1999), "A multi-country comparison of the drive for IMC", Journal of advertising Research, 39 (1), 21-38.

Kitchen, P. J., and Li, T. (2005), "Perceptions of integrated marketing communications: a Chinese ad and PR agency perspective", International Journal of Advertising, 24 (1), 51-78.

Kitchen, P. J. (2017), “Guest editorial - Integrated marketing communications - current status, future developments", European Journal of Marketing, 51 (3), 394-405. 
Kitchen, P. J., and Tourky, M. (2015), Integrated Communications in the Postmodern Era. London: Palgrave Macmillan UK.

Kitchen, P. J., Kim, I., and Schultz, D.E. (2008), “Integrated marketing communications: Practice leads theory", Journal of advertising research, 48 (4), 531-546.

Kitchen, P.J., Schultz, D.E., Kim, I., Han, D. \& Li, T. (2004), "Will agencies ever "get" (or understand) IMC?", European Journal of Marketing, 38 (11/12), 1417-1436.

Kliatchko, J. (2005), "Towards a new definition of integrated marketing communications (IMC)", International Journal of Advertising, 24 (1), 7-34.

Kliatchko, J. (2008), "Revisiting the IMC construct: A revised definition and four pillars", International Journal of Advertising, 27 (1), pp 133-160.

Kliatchko, J., and Schultz, D. E. (2014), “Twenty years of IMC: A study of CEO and CMO perspectives in the Asia-Pacific region", International Journal of Advertising, 33 (2, pp 373390.

Luxton, S., Reid, M., and Mavondo F. (2015), "Integrated marketing communication capability and brand performance", Journal of Advertising, 44 (1, pp 37-46.

Luxton, S., Reid, M., and Mavondo F. (2017), "IMC capability: antecedents and implications for brand performance", European Journal of Marketing, 51 (3), 421-444.

McCarthy, J., Rowley, J., Jane Ashworth, C., \& Pioch, E. (2014), “Managing brand presence through social media: the case of UK football clubs", Internet Research, 24 (2), 181-204.

Manoli, A. E., and Davies, M. (2014), “IMC and the practitioners" strategy paradox", paper presented at the International Conference on Research in Advertising (ICORIA), 26-28 June, Amsterdam. 
Manoli, A. E., and Hodgkinson, I. R. (2017), "Marketing outsourcing in the English Premier League: the rights holder/agency interface", European Sport Management Quarterly, 17 (4), 436-456.

Manoli, A.E., and Kenyon, J.A. (2018), Football and Marketing in S. Chadwick, D. Parnell, P. Widdop \& C. Anagnostopoulos (Eds.) Routledge Handbook of Football Business and Management, (pp. 88-100), Oxon: Routledge.

Mortimer, K., and Laurie S. (2017), “The internal and external challenges facing clients in implementing IMC”, European Journal of Marketing, 51 (3), 511-527.

Myers, M. D. (2009), Qualitative research in business and management. London: Sage.

Ots, M., and Nyilasy, G. (2017), "Just doing it: theorising integrated marketing communications (IMC) practices", European Journal of Marketing, 51 (3), 490-510.

Ots, M. and Nyilasy, G. (2015), "Integrated Marketing Communications (IMC): Why Does It Fail?: An Analysis of Practitioner Mental Models Exposes Barriers of IMC Implementation", Journal of Advertising Research, 55 (2), 132-145.

Patti, C. H., Hartley, S. W., van Dessel, M. M., and Baack, D. W. (2017), "Improving integrated marketing communications practices: A comparison of objectives and results”, Journal of Marketing communications, 23 (4), 351-370.

Parganas, P., Anagnostopoulos, C. \& Chadwick, S. (2015), “'You'll never tweet alone': Managing sports brands through social media”, Journal of Brand Management, 22 (7) 551568.

Phillips, M. E. (1994), “Industry mindsets: Exploring the cultures of two macroorganizational settings", Organization Science, 5 (3), 384-402. 
Porcu, L., del Barrio-García, S., and Kitchen P. J. (2017), “Measuring integrated marketing communication by taking a broad organisational approach”, European Journal of Marketing, $51(3), 692-718$.

Porcu, L., del Barrio-García, S., Alcántara-Pilar, J.M., and Crespo-Almendros, E., (2017), "Do adhocracy and market cultures facilitate firm-wide integrated marketing communication (IMC)?”. International Journal of Advertising, 36 (1), 121-141.

Reinold, T., and Tropp, J. (2012), "Integrated marketing communications: How can we measure its effectiveness?”, Journal of Marketing Communications, 18 (2), 113-132.

Rose, P. B. (1996), "Practitioner opinions and interests regarding integrated marketing communications in selected Latin American countries", Journal of Marketing Communications, 2 (3), 125-139.

Schultz, D. E. (1992), "Integrated marketing communications", Journal of Promotion Management, 1 (1), 99-104.

Schultz, D. E., Kim, I. and Kang, K. (2014), Integrated marketing communication research in H. Cheng (Ed.) The handbook of international advertising research, (pp. 455-483), London: Wiley Blackwell.

Schultz, D. E., Patti, C.H. and Kitchen, P.J. (2013), The evolution of integrated marketing communications: The customer-driven marketplace, London: Routledge.

Schultz, D. E., Chu, G., and Zhao, B. (2016), "IMC in an emerging economy: the Chinese perspective", International Journal of Advertising, 35 (2), 200-215.

Šerić, M. (2018), “Content analysis of the empirical research on IMC from 2000 to 2015”, Journal of Marketing Communications, 24 (7), 647-685. 
Tafesse, W. and Kitchen, P.J. (2017), "IMC-an integrative review”, International Journal of Advertising, 36 (2), 210-226.

Yin, R. K. (2009) Case Study Research: Design and Methods. 4th edn. Thousand Oaks, CA: Sage. 